\title{
Citologia dos lavados traqueobrônquico (LTB) e broncoalveolar (LBA) de bezerros holandeses sadios durante o primeiro mês de vida ${ }^{1}$
}

\author{
Fernando J. Benesi²*, Lucia Wachholz ${ }^{3}$, Heloisa G. Bertagnon ${ }^{3}$, Marta L.R. Leal ${ }^{3}$, \\ Enio Mori ${ }^{3}$ e Wilson R. Fernandes ${ }^{2}$
}

\begin{abstract}
Benesi F.J., Wachholz L., Bertagnon H.G., Leal M.L.R., Mori E. \& Fernandes W.R. 2012. [Cytology of tracheobronchial and bronchoalveolar lavage in healthy Holteins calves during the first month of life.] Citologia dos lavados traqueobrônquico (LTB) e broncoalveolar (LBA) de bezerros holandeses sadios durante o primeiro mês de vida. Pesquisa Veterinária Brasileira 32(3):267-270. Departamento de Clínica Médica, Faculdade de Medicina Veterinária e Zootecnia, Universidade de São Paulo, Av. Prof. Dr. Orlando Marques de Paiva 87, São Paulo, SP 05508-270, Brazil. E-mail: febencli@usp.br

The neonatal calf is a critical moment for adaptation of the newborn to extra uterine life. The respiratory tract is functionally very demanded and often affected by disease, resulting in direct loss of their function and causing serious economic losses in livestock. The basic point to reduce these losses is appropriate clinical evaluation of neonates; but the diagnosis based solely in physical examination is very difficult to establish. The use of complementary analysis such cytology of the respiratory tract becomes an important diagnostic tool; however their findings must be standardized in the face of different techniques employed. This research studied the dynamics of the cellularity of the bronchoalveolar and tracheobronchial region obtained through lung lavage harvested by nasotracheal catheterization technique and tracheocenthesis respectively, during the first month of life of healthy calves. The tracheobronchial cytology was influenced by the time, showing decreased number of alveolar macrophages and greater number of neutrophils, possibly increased by local irritation caused by the technique, which was repeated sequentially, and/or through greater stimulation of inhaled microorganisms deposited in this region. In the bronchoalveolar region no variation in the cellular constituents in function of time was found. The results allowed the conclusion the cell population of the tracheobronchial region has changed over the week-old calves, possibly due to the technique used and/or to the normal region physiology, represented by higher magnitudes of neutrophils. Otherwise, the cells of the broncholaveolar region showed a stable behavior during the first month of life of newborn calves, presenting numerical predominance of alveolar macrophages.
\end{abstract}

INDEX TERMS: Citology, lung lavage, tracheocentesis, nasotracheal catheterization technique, calves.

RESUMO.- 0 período neonatal dos bezerros é um momento crítico para adaptação do recém-nascido à vida extra uterina e o sistema respiratório, um dos mais exigidos funcionalmente, é frequentemente afetado por enfermidades, re-

\footnotetext{
${ }^{1}$ Recebido em 9 de setembro de 2011.

Aceito parta publicação em 25 de janeiro de 2012.

Projeto Financiado pela FAPESP, Auxílio Pesquisa no.2000/06783-7.

${ }^{2}$ Departamento de Clínica Médica, Faculdade de Medicina Veterinária e Zootecnia (FMVZ), Universidade de São Paulo (USP), Av. Prof. Dr. Orlando Marques de Paiva 87, São Paulo, SP 05508-270, Brasil. *Autor para correspondência: febencli@usp.br

${ }^{3}$ Pós-Graduandos do Programa de Clínica Veterinária, Departamento de Clínica Médica, FMVZ-USP, São Paulo, SP.
}

dundando no prejuízo direto da sua função e acarretando perdas econômicas importantes na pecuária. 0 ponto básico para reduzir estas perdas, é representado pela adequada avaliação clínica dos neonatos, todavia o diagnóstico baseado exclusivamente no exame físico é muito difícil de ser estabelecido. 0 uso de exames complementares como a citologia do trato respiratório torna-se uma ferramenta diagnóstica importante nestes casos, porém faz-se necessário, padronizar seus achados frente às diferentes técnicas empregadas para a sua obtenção. Assim, o presente estudo propôs-se acompanhar as variações dos constituintes celulares da região traqueobrônquica e broncoalveolar obtidos por lavados respiratórios pelos métodos de traqueocente- 
se e por colheita nasotraqueal respectivamente, durante o primeiro mês de vida de bezerros sadios. Observou-se alteração no quadro citológico ao longo do tempo, quando a região traqueobrônquica foi lavada, expresso por diminuição da porcentagem de macrófagos alveolares, com aumento de neutrófilos, possivelmente, por maior irritação local provocada pela técnica, que se repetiu sequencialmente e/ou por maior estimulo de microorganismos inalados depositados nesta região. Na região broncoalveolar, não encontraram-se variações nos constituintes celulares em função do tempo. Os resultados permitiram a conclusão que a população celular da região traqueobrônquica modificou-se ao longo das semanas de vida dos bezerros, possivelmente pela técnica empregada e/ou fisiologia normal da região, sendo representadas por maiores magnitudes de neutrófilos. De modo diverso, na região broncolaveolar, as células evidenciaram um comportamento estável durante o primeiro mês de vida dos bezerros neonatos, apresentando predomínio numérico dos macrófagos alveolares.

TERMO DE INDEXAÇÃO: Citologia, lavado pulmonar, traqueocentese, sondagem nasotraqueal, bezerros.

\section{INTRODUÇÃO}

0 período neonatal dos bezerros, que compreende o primeiro mês de vida do neonato, tem como ponto central o seu direcionamento para a adaptação do recém-nascido à vida extra uterina. Caracteriza-se por ter as maiores taxas de mortalidade de bezerros (Benesi 1993), sendo o sistema respiratório freqüentemente afetado por enfermidades, redundando no prejuízo direto da sua função, com evolução para a morte ou desenvolvimento retardado de animais sobreviventes (Radostits et al. 2000).

0 ponto básico para reduzir estas perdas, é representado pela adequada avaliação clínica dos neonatos, para estabelecer o pronto diagnóstico, o tratamento precoce e a resolução da enfermidade. No entanto, o diagnóstico baseado exclusivamente no exame físico é muito difícil de ser estabelecido e na maioria dos casos, necessita de informações de exames complementares para reconhecimento, terapia e prognóstico corretos da enfermidade que acomete o animal (Radostitis et al. 2000, Nogueira \& Pardo 2001, Gonçalves 2004).

Para adequada interpretação fundamentada dos resultados desses exames auxiliares, necessita-se da adequada padronização dos métodos à espécie animal em estudo, existência de valores de referência estabelecidos em animais sadios e que considerem possíveis variações fisiológicas decorrentes da raça, sexo, idade e estresses naturais, assim como por influência de intervalos de colheitas realizadas (Pringle et al. 1988, Barros et al. 1994, Fernandes et al. 2000, Bertagnon et al. 2007, Hennig-Pauka et al. 2007, Griffin et al. 2010).

Por serem raras as pesquisas nacionais que estudaram a citologia de lavados respiratórios em bezerros (Barros et al. 1994, Gonçalves 2004), inexistindo estudos nesses animais no período neonatal (Gonçalves et al. 2011), propôs-se acompanhar, de forma quantitativa, as variações dos constituintes celulares da região traqueobrônquica e bron- coalveolar, avaliadas por meio do exame citológico, em lavados seriados obtidos pelos métodos de traqueocentese e por colheita nasotraqueal, durante o primeiro mês de vida e em intervalos de sete dias.

\section{MATERIAL E MÉTODOS}

Foram selecionados 20 bezerros machos, da raça Holandesa Preto e Branco, sadios, com idade entre o primeiro e o sexto dia de vida, que mamaram o colostro, provenientes de propriedades localizadas em municípios do Estado de São Paulo. Estes animais foram mantidos em gaiolas individuais no setor experimental da clínica de bovinos e pequenos ruminantes da FMVZ-USP e alimentados com 2 litros de sucedâneo de leite ${ }^{4}$ duas vezes por dia. Receberam também água, ração peletizada, 'capim verde e feno a vontade. Somente os animais sadios foram utilizados na pesquisa, sendo a higidez verificada através de exames físicos diários, e exames laboratoriais semanais (hemograma, bioquímica sérica e hemogasometria arterial).

Os animais foram distribuídos aleatoriamente em dois grupos, cada um com dez bezerros, agrupados de acordo com a técnica e o local utilizados para a colheita do lavado respiratório, sendo no Grupo 1 (G1), realizada a colheita do lavado traqueobrônquico (LTB) pela técnica de traqueocentese, e no Grupo 2 (G2), realizado o lavado broncoalveolar (LBA) pela técnica de sondagem nasotraqueal. A primeira colheita foi efetuada em bezerros com 5 a 7 dias de vida e a seguir, semanalmente até completarem aproximadamente um mês de vida, totalizando quatro colheitas.

No G1, puncionou-se a traquéia na região do segundo anel traqueal com uma agulha de $14 \mathrm{~g}$ x $5 \mathrm{~cm}$, e através dela, introduziu-se um catéter de polietileno ${ }^{5}$ até a bifurcação traqueal. 0 lavado foi realizado após a instilação de quatro alíquotas de $10 \mathrm{ml}$ cada, de solução fisiológica $0,9 \%$ a temperatura ambiente e o conteúdo foi recuperado por aspiração imediata com seringa plástica com capacidade de $60 \mathrm{ml}$.

No G2, uma sonda de silicone estéril de 8,0mm de diâmetro e $100 \mathrm{~cm}$ de comprimento foi introduzida na narina dos bezerros previamente lavada, direcionada a traquéia e inserida até encontrar-se resistência a sua progressão, na região dos brônquios principais. Na sequência era introduzido pela sonda guia, uma outra sonda ${ }^{6}$, com $2 \mathrm{~mm}$ de diâmetro e $110 \mathrm{~cm}$ de comprimento, através da qual se realizava o lavado como o descrito para o G1.

Posteriormente uma alíquota de $200 \mu \mathrm{l}$ do lavado era centrifugada a $28 \mathrm{G}$, por 6 minutos em citocentrífuga, sendo o sobrenadante desprezado, e a partir do precipitado, confeccionado um esfregaço fixado em álcool metílico p.a. e corado pelo método de Rosenfeld (1947). A leitura das lâminas foi realizada por uma única pessoa em microscopia óptica de imersão, quantificando-se 400 células por lâmina de acordo com suas características morfológicas e tintoriais.

A análise estatística foi realizada utilizando o programa estatístico computadorizado Minitab (1998). Para cada grupo e cada semana de colheita (1aa $2^{\underline{a}}, 3^{\underline{a}}$ e $\left.4 \stackrel{a}{a}\right)$, foram calculadas as medianas e percentis, utilizando testes não-paramétricas de Friedman e de Mann-Whitney. Foram consideradas diferenças significativas quando $p$ apresentou valores iguais ou inferiores a 0,05 (Sampaio 1998).

\section{RESULTADOS E DISCUSSÃO}

Os resultados medianos obtidos das porcentagens de cada tipo celular conforme o tempo, em cada grupo estão ex-

\footnotetext{
${ }^{4}$ Quality Milk®.

${ }^{5}$ Intracathy BD®.

${ }^{6}$ Sonda gástrica longa número 8.
} 
pressos no Quadro 1. Pode-se observar que houve alteração na citologia ao longo do tempo, quando a região traqueobrônquica foi lavada, caracterizado por diminuição da porcentagem de macrófagos alveolares, aumento de neutrófilos e oscilações na população de linfócitos. Quando a região broncoalveolar foi lavada, não encontrou-se variações nos constituintes celulares em função do tempo, evidenciando-se que a região traqueobrônquica possuiu maiores magnitudes de neutrófilos enquanto que a broncoalveolar, não predomínio de macrófagos alveolares durante o primeiro mês de vida.

A execução semanal dos exames complementares e a realização diária do exame físico dos bezerros, permitiu verificar que os mesmos estavam livres de alterações respiratórias. Assim o progressivo aumento dos neutrófilos observado no G1 sugere que a traqueocentese foi mais invasiva, diferindo das evidências e conclusões de Bower (1977) que classificou a técnica como atraumática. Fatores como baixo volume recuperado da solução instilado para o lavado ( cerca de 0,5 a 20\%), e a presença de hemáceas nos esfregaços já foram evidenciados por outros pesquisadores ao realizarem traqueocentese (Barros et al. 1994, Gonçalves 1997, Hennig-Pauka et al. 2007) e poderiam suportar a hipótese de que esta técnica de colheita é mais traumática, principalmente se utilizada sequencialmente.

Diferenças nos valores dos constituintes do lavado do trato respiratório, conforme o local de lavagem, já foram relatadas por outros pesquisadores em várias espécies animais (Pringle et al. 1988, Barros et al. 1994, Fernandes et al. 2000, Hennig-Pauka et al. 2007, Bertagnon et al. 2007, Griffin et al. 2010). Provavelmente estas diferenças ocorrem devido a estimulação que microorganismos inalados provocam no trato respiratório, já que partículas aerolizadas inaladas não filtradas pelo trato respiratório anterior,

Quadro 1. Valores das medianas dos diferentes tipos celulares de acordo com os grupos submetidos às técnicas detraqueocentese para obtenção do LTB (Grupo 1) e de sondagem nasotraqueal para obtenção de LBA (Grupo 2), segundo as semanas durante o primeiro mês de vida dos animais. São Paulo, 2011

\begin{tabular}{|c|c|c|c|c|c|}
\hline \multirow{3}{*}{\multicolumn{2}{|c|}{ Grupos }} & \multirow{2}{*}{\multicolumn{4}{|c|}{$\begin{array}{l}\text { Porcentagens dos diferentes tipos } \\
\text { celulares da região respiratória } \\
\text { Tempos (semanas) }\end{array}$}} \\
\hline & & & & & \\
\hline & & 1 & 2 & 3 & 4 \\
\hline \multirow[t]{6}{*}{ Grupo 1} & Macrófagos alveolares & $62,15^{\mathrm{aA}}$ & 34,30 aA & $34,50^{\mathrm{aA}}$ & $20,15^{b A}$ \\
\hline & Células gigantes & $0,15^{\mathrm{aA}}$ & $0^{\mathrm{aA}}$ & $0^{\mathrm{aA}}$ & $0^{\mathrm{aA}}$ \\
\hline & Neutrófilos & $15,30 \mathrm{bA}$ & 59,40 aA & $63,40^{\mathrm{aA}}$ & $75,80^{\mathrm{aA}}$ \\
\hline & Células epiteliais ciliadas & $0^{\mathrm{aA}}$ & $0^{\mathrm{aA}}$ & $0^{\mathrm{aA}}$ & $0^{\mathrm{aA}}$ \\
\hline & Linfócitos & $2,55^{\mathrm{aA}}$ & $4,00^{\mathrm{aA}}$ & $0,80^{\mathrm{bA}}$ & $1,65^{\mathrm{abA}}$ \\
\hline & Eosinófilos & $0^{\mathrm{aA}}$ & $0^{\mathrm{aA}}$ & $0^{\mathrm{aA}}$ & $0^{\mathrm{aA}}$ \\
\hline \multirow[t]{6}{*}{ Grupos 2} & Macrófagos alveolares & $75,50^{\mathrm{aA}}$ & 63,50 a & $75,65^{a B}$ & $70,55^{\mathrm{aB}}$ \\
\hline & Células gigantes & $0^{\mathrm{aA}}$ & $0,30^{\mathrm{aA}}$ & $0^{\mathrm{aA}}$ & $0^{\mathrm{aA}}$ \\
\hline & Neutrófilos & $12,40^{\mathrm{aA}}$ & $3,65^{a B}$ & $19,30 \mathrm{aB}$ & $11,00^{\mathrm{aB}}$ \\
\hline & Células epiteliais ciliadas & $0^{\mathrm{aA}}$ & $0,25^{\mathrm{aA}}$ & $0^{\mathrm{aA}}$ & $0,90^{\mathrm{aA}}$ \\
\hline & Linfócitos & $2,15^{\mathrm{aA}}$ & $2,30^{\mathrm{aA}}$ & $2,40^{\mathrm{aA}}$ & $1,00^{\mathrm{aA}}$ \\
\hline & Eosinófilos & $0^{\mathrm{aA}}$ & $0^{\mathrm{aA}}$ & $0^{\mathrm{aA}}$ & $0^{\mathrm{aA}}$ \\
\hline
\end{tabular}

Medianas com letras minúsculas não coincidentes em mesma linha, indicam diferença estatística entre as semanas dentro de cada técnica $(\mathrm{p} \leq 0,05)$. Medianas com letras maiúsculas não coincidentes em mesma coluna, indicam diferença estatística entre técnicas dentro de cada semana $(\mathrm{p} \leq 0,05)$. se depositam na região traqueobrônquica, estimulando uma resposta celular caracterizada pelo aumento de neutrófilos, as células de defesa mais mobilizadas na inflamação (Griffin et al. 2010).

Apesar de regiões mais distais do trato respiratório possuírem porcentagens maiores de macrófagos (Griffin et al. 2010), estas células ainda predominaram sobre a porcentagem de neutrófilos na região traqueobrônquica de bezerros sadios na pesquisa realizada por Gonçalves et al. (2004). Possivelmente os resultados da análise citológica foram discrepantes da presente pesquisa, porque os autores utilizaram uma técnica de colheita menos invasiva (sonda nasotraqueal), por uma única vez e os bezerros eram mais velhos (1a 6 meses de idade). Como a atividade bactericida de neutrófilos é deficiente durante o período neonatal (Hauser et al. 1986) acredita-se que os mesmos precisaram ser mobilizados em maior número para garantir a eliminação eficaz de bactérias e a higidez do animal, já que o mesmo predomínio celular foi encontrado no trato respiratório de bezerros com menos de 30 dias por Fogarty et al. (1983).

As porcentagens da população celular do trato respiratório do G2 não sofreu influencia do tempo. A proporção entre macrófagos/neutrófilos se mostrou com valores bem maiores no decorrer do período neonatal quando comparados com aqueles obtidos para o grupo G1 sendo semelhantes aos valores encontrados por Yeo et al. (1993) e Gonçalves (1997), evidenciando que esta técnica e que o intervalo de colheita de amostras não causou inflamação local e que os macrófagos alveolares residentes foram eficientes em manter um estável e contínuo sistema de fagocitose sem necessitar de um recrutamento de outras células de defesa para o local.

\section{CONCLUSÕES}

Os resultados da avaliação citológica do trato respiratório de bezerros neonatos sadios permitiram concluir que:

- A região traqueobrônquica apresenta diminuição progressiva da porcentagem de macrófagos alveolares com aumento proporcional de neutrófilos ao longo do primeiro mês de vida dos animais, havendo inversão destes valores, devido a técnica de colheita - traqueocentese - ser mais traumática bem como o local da colheita ser reconhecidamente de maior exposição aos patógenos inalados.

- Não há variações nos constituintes celulares na região broncoalveolar de bezerros sadios em função da evolução etária, sendo a citologia caracterizada por predomínio de macrófagos; pois a região não é submetida aos mesmos desafios que a traqueobrônquica.

\section{REFERÊNCIAS}

Benesi F.J. 1993. Síndrome asfixia neonatal dos bezerros: importância e avaliação crítica. Arq. Esc. Med. Vet. Univ. Fed. Bahia 16:38-48.

Barros M.S.R.M., Castro R.S., Tabosa J.H.C., Brito M.F. \& Amaral B. 1994. Colheita do fluído brônquico-alveolar de bezerros através da traqueocêntese transcutânea. Arq. Bras. Med. Vet. Zootec. 46:41-49.

Bertagnon H.G., Silva P.E.G., Wachholz L., Leal M.L.R., Fernandes W.R. \& Benesi F.J. 2007. Imunoglobulinas no trato respiratório de bezerros sadios durante o primeiro mês de vida. Pesq. Vet. Bras. 27(12):487-490 
Bower J. 1977. A pulmonary diagnostic technique. Calif. Vet. 31:11-13.

Fernandes W.R., Mori E. \& Sanches A. 2000. Avaliação citológica de lavados traqueobrônquicos e broncoalveolares em cavalos clinicamente sadios pelo método de coloração de Rosenfeld. Arq. Bras. Med. Vet. Zootec. 52:604-609.

Forgarty U., Quinn P. \& Hannan J. 1983. Bronchopulmonary lavage in the calf: A new technique. Irish Vet. 37:35-38.

Griffin D., Chengappa M.M., Kuszak J. \& Scott McVey D. 2010. Bacterial pathogens of the bovine respiratory disease complex. Vet. Clin. North Am., Food. Anim. Pract. 26:381-394.

Gonçalves R.C.1997. Estudo clínico e citológico em bezerros clinicamente sadios e portadores de broncopneumonia moderada e grave. Tese de Doutorado em Patologia, Faculdade de Ciências Agrárias e Veterinárias, Universidade Estadual Paulista, Botucatu, SP. 144p.

Gonçalves R.C., Mattos M.C.F.I, Kuchembuck M.R.G., Lopes R.S. \& Borges A.S. 2004. Lavagem traqueobrônquica por sondagem nasotraqueal em bezerros Arq. Bras. Med. Vet. Zootec. 56(3):307-311.

Gonçalves R.C., Rocha A.E.A., Silva A.A., Takahira R.K., \& Chiacchio S.B. 2011. Influência da suplementação de vitamina $E$ na profilaxia e tratamento da broncopneumonia moderada e grave em bezerros Pesq. Vet. Bras. 31(2):127-135.

Hauser M.A., Koob M. D. \& Roth J.A. 1986. Variation of neutrophil function with age in calves. Am. J. Vet. Res. 74:152-153.

Hennig-Pauka I., Bremerich S., Nienhoff H., Schroder C., Ganter M., Blecha F., Waldmann K.H. \& Gerlach G.F. 2007. Comparison of three common methods of lung lavage in healthy pigs. J. Vet. Med. A 54:428-433.

Minitab 1998. The Student Edition of MINITAB Statistical Software Adapted for Education - 12,1 Release: User's Manual. Addison-Wesley, New York. 624p.

Nogueira R.B. \& Pardo P.E. 2001. Terapêutica do sistema respiratório, p.206-215. In: Andrade S.F. (Ed.), Manual de Terapêutica Veterinária. 2ª ed. Rocca, São Paulo.

Pringle J.K., Viel L., Shewen P.E., Willoughby R.A., Martin S.W. \& Valli V.E. 1988. Bronchoalveolar lavage of cranial and caudal lung regions in selected normal calves: Cellular, microbiological, immunoglobulin, serological and histopathological variables. Can. J. Vet. Res. 52:239-248

Radostits O.M., Gay C.C., Blood D.C. \& Kenneth H.W. 2000. Clínica Veterinária: um tratado de doenças dos bovinos, ovinos, suínos, caprinos e eqüinos. 9a ed. Guanabara-Koogan, São Paulo. 1737p.

Rosenfeld G. 1947. Corante pancrômico para hematologia e citologia clínica: Nova combinação dos componentes do May-Grünwald e do Giemsa num só corante de emprego rápido. Memórias do Instituto Butantan 20:329-335.

Sampaio I.B.M. 1998. Estatística Aplicada à Experimentação Animal. Fundação de Ensino e Pesquisa em Medicina Veterinária e Zootecnia - Departamento de Zootecnia, UFMG. 221p.

Yeo S.P., Stokes C.R., Taylor F.G.R. \& Bourne F.J. 1993. Maturation of cellular defence in the respiratory tract of young calves. Res. Vet. Sci. 55(3):292297. 